\title{
Knowledge and Practices of Adolescents about Risk Factors for Non-Communicable Diseases at Kabwohe Health Centre IV.
}

\author{
Dickson Agaba ${ }^{a}, 1$, Allan Muhumuza ${ }^{a}$ \\ a Faculty of Nursing and Health Sciences, Bishop Stuart University
}

\begin{abstract}
\end{abstract}

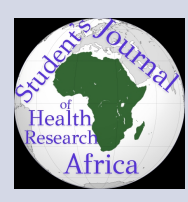

Background: ${ }^{a}$

Non-communicable diseases (NCDS) are the leading cause of mortality and morbidity globally and one of the major health challenges of the 21stcentury. Adolescents are involved in lifestyle behaviours that foster NCDs development later on in the future because of their lack of knowledge about NCDs risk factors. However, there is a paucity of studies that have dealt with knowledge and practices of adolescents about NCDs risk factors. This study therefore aimed at assessing the knowledge and practices of adolescents about NCDs risk factors at Kabwohe HCIV.

\section{Methods:}

A health center-based cross-sectional study was conducted among 95 adolescents receiving health-related care services at Kabwohe health center IV. Information was collected using a structured questionnaire and analyzed using SPSS version 20. Descriptive statistics and bivariate analysis were used in the statistical interpretation.

\section{Results:}

The overall knowledge of adolescents about NCDs risk factors was $60 \%$. Concerning diet that has fruits, the majority $60(62.4 \%)$ took fruits at least once, twice or thrice in a week while $35(37.6 \%)$ took fruits more frequently as in four, five times or days as they are indicated in the table above. About vegetable intake,57(60\%) percent took a diet with vegetables once, twice, or thrice in a week compared to the $38(40 \%)$ that took a diet with vegetables many times a week.44(35.8\%) took sugary foods more often i.e. many times in a week compared to the $61(64.3 \%)$ that took them less often. Concerning the intake of solid fats or fried food, 52(54.7\%) took fried foods more occasionally in a week and a day compared to the $43(45.3 \%)$ that took fried diet less often. The following variables were significantly associated with knowledge about NCDs risk factors: area of residence $(p=.0028)$, Level of education $(p=.0181)$.

\section{Conclusion:}

Average levels of knowledge were recorded among adolescents receiving care at Kabwohe health center IV though there were high practicing percentages of the risky healthy lifestyle behaviours that foster NCDs development for example most of the adolescents who participated in the study didn't engage in physical activities to stay healthy and they also don't take daily servings of fruits and vegetables in their diet

\footnotetext{
${ }^{a}$ email: agabadickson53@gmail.com date submitted: 13th/04/2021 date accepted: 28th/04/2021
}

\section{Background of the study}

Non-communicable diseases (NCDS) are the leading cause of mortality and morbidity globally and one of the major health challenges of the $21^{\text {st }}$ century (WHO, 2010). In 2016, NCDs were responsible for $71 \%(41$ million) of the 57 million deaths which 
occurred globally. The major NCDs responsible for these deaths included cardiovascular diseases (17.9million deaths, accounting for $44 \%$ of all NCD deaths and $31 \%$ of all global deaths); cancers (9million deaths, $22 \%$ of all NCD deaths, and $16 \%$ of all global deaths); chronic respiratory diseases (3.8 million deaths, $9 \%$ of all NCD deaths and $7 \%$ of all global deaths, and diabetes (1.6 million deaths, $4 \%$ of all NCD deaths and $3 \%$ of all global deaths. The global probability of dying from one of the four main NCDs in 2016 was $18 \%$, with a slightly higher risk for males (22\%) than for females (15\%) (Wensonga et al., 2017).

Among the main contributing factors are older age and unhealthy lifestyle-related behaviours which are mostly adopted by adolescents hence the term "lifestyle-related diseases". Adolescents are classified as individuals between the ages of 10 to 19 years (WHO, 2010) and it is a well-known fact that most lifestyle-related risk factors for NCDs are laid down in this period (WHO, 2010). According to Gamage et al., (2018), evidence on the current knowledge and lifestyle-related practices of adolescents would immensely help both the health and education sectors with planning and implementation of much-needed programs for school children.

According to the study done in Colombia in Sri Lanka among adolescents in high schools, 43\% of the students had overall knowledge on NCDs and lifestyle practices among the study group were poor. Despite the above, a higher proportion (56.6\%) of students had good knowledge of Coronary Artery Disease, health diet (74.9\%), and physical activity (56.6\%) as protective factors. (AU Gamagel et al., 2018). According to the study done on University students in Saudi Arabia respondent's knowledge was not good, but they had a good attitude. They were unaware of few important factors implicated in the CVD, like stress, diabetes mellitus, chronic renal failure, increased use of salt, excessive use of organ meat such as liver, kidney, and brain, sedentary lifestyle, waist circumference $>40$ inches, BMI >30 (Rahamathulla et al., 2020).

In sub-Saharan Africa, much attention has been paid to communicable diseases yet there is evidence to suggest that the burden of NCDs is increasing rapidly in most parts of the region (Namusisi et al., 2011). Here the prevalence of NCDs is projected to cause nearly $75 \%$ as many deaths as communicable, maternal, perinatal, and nutritional diseases by 2020 (WHO, 2011) and Uganda is one of the countries found in Sub-Saharan Africa where the burden of NCDs in terms of disability-adjusted life-years increases and continues to stress the already stressed and under-resourced health systems. Several studies done in Africa show that the level of knowledge concerning NCDs among adolescents is high, yet the occurrence of the diseases has been persistently high.

NCDs are a major health problem in Uganda. The success of primary preventive measures and timely medical attention immediately following NCD is influenced by the public's knowledge on risk factors and their practice towards their prevention (Kaddumukasa et al., 2015). Adolescents are involved in lifestyle behaviours that foster NCDs development later on in the future because of their lack of knowledge about NCDs risk factors. (Nunes Heg et al., 2017). However, there are limited documented studies on knowledge and practices about NCDs risk factors among adolescents in Uganda (Mondo et al., 2013). Thus, this research is aimed at assessing the knowledge and practices about NCDs risk factors among adolescents in rural areas in particular Kabwohe Health Centre IV to develop evidencebased NCDs prevention policies and public health interventions.

\section{Study design}

\section{METHODS}

A descriptive cross-sectional study design that employed quantitative methods was carried out since data was collected at one point in time from a representative sample.

\section{Study settings}

The study was carried out from Kabwohe Health Centre IV. It is a rural government health center located in Sheema municipality, Sheema County, Sheema district, Western Uganda.

\section{Study population}

The study population included all adolescents of ages 10-19 receiving outpatient care at Kabwohe Health Centre IV during the time of data collection, who voluntarily agreed to participate in the study.

\section{Sample size determination}

Using Kish and Leslie's standard formula (1965), $\mathrm{N}=\mathrm{Z}^{2} \mathrm{PQ} / \mathrm{E}^{2}$.

Where $\mathrm{N}$ is the sample size,

Z-score responding to $95 \%$ of confidence interval which is 1.96, 
$\mathrm{P}=$ percentage of respondents, estimated to be $50 \%$.

$\mathrm{Q}=1-\mathrm{P}=1-0.5=0.5$

$\mathrm{E}=$ Level of error expected which is $5 \%(0.05)$

$\mathrm{N}=(1.96)^{2} \times 0.5(0.5) / 0.05^{2}$

$\mathrm{N}=384$

The sample size will be 384

The study was adjusted for finite population,

Using Fisher's et al. (1998) formula;

$n f=n /(1+(n / N)$

Where; $\mathrm{nf}=$ desired sample for population $<10$ 000

$\mathrm{n}=$ calculated sample size for population $>10000$.

$\mathrm{N}=$ estimate of the population size (125)

$\mathrm{nf}=384 /(1+(384 / 125)$

$=384 / 4.072$

$\mathrm{nf}=94.3$ respondents; 95 respondents was considered.

\section{Sampling technique}

A simple random sampling technique was used to select the study participants. It involved the selection of participants by using a numbered list of daily OPD attendees as a sampling frame. From this list, a method of the lottery was used to randomly select participants and this was done by writing each participant number on a separate piece of paper. These pieces of paper were then mixed and put into a box and numbers were drawn out of the box randomly without replacement. Approximately ten participants were randomly sampled on every working day.

\section{Inclusion criteria}

The study included all adolescents who were available during the data collection period and willing to participate after understanding all about my research study.

\section{Exclusion criteria}

The study excluded adolescents who could not give responses like critically ill ones, those unable to hear or communicate, and those with mental health problems.

\section{Research Instruments}

Questionnaire method: Researcher administered questionnaires were used as a tool for data collection.

The questionnaires were prepared in English and then translated into Runyankore, Rukiga to make it simple during administration for the interview with the respondents.

Questionnaires were administered to the respondents by the researcher to mainly collect quantita- tive data and the tool contained close-ended (structured) questions and open-ended ones as it was mainly guided by the two main objectives.

\section{Data Quality control.}

\section{Validity}

The data collection instruments were designed and pretested in the field for two days to check; validity and reliability of instruments and adjustments were made accordingly before the actual data collection or distribution of the tools.

\section{Reliability}

Collected data was scrutinized at end of each working day to ensure completeness and accuracy in recording and consistency of information given by the respondents. The researcher would crosscheck all instruments on daily basis to ensure completeness before data entry.

\section{Data management}

The research instrument would be checked for errors and omissions to ensure consistency, completeness, and accuracy in filling of the interview schedule and this would be done in the field immediately after the questionnaires had been filled

Questions in the tools were pre-coded to help the researcher get uniform quantified data and the data collected from respondents was kept safe and confidential, the recorded instruments were put together in a file before analysis was made.

\section{Data analysis}

Data were coded, checked, and analyzed using Statistical Package for the Social Sciences (SPSS windows version 20) to establish the relationship between the KP and NCDs risk factors. Univariate and bivariate analysis was done and significance was considered when $P$ value $\leq 0.05$ and insignificance was considered when $P$ value $>0.05$.

\section{Data presentation}

Data was presented by the use of variable tables with the help of a few representative charts, to ease the process of interpretation of findings. The nontabulated data were descriptively reported

\section{Dissemination of Results}

The findings of the study were compiled into a report and three copies were produced and disseminated to;

The researcher, Bishop Stuart University Nursing Campus Library, Kabwohe Health Centre IV.

\section{Ethical considerations}


The researcher obtained an introductory letter from the Head of Nursing Department at Bishop Stuart University. Permission was also obtained from the Sheema District Health officer and Kabwohe HCIV management. Informed consent was always sought from respondents and they will be assured of the confidentiality of the information they will provide.

\section{RESULTS}

\section{Demographic characteristics of respondents}

Out of 95 of the total respondents, $29.5 \%$ of respondents are within the ages of 10-15 years with the majority $70.5 \%$ within the ages of $15-19$. The majority of the respondents were females (55.8\%) and $44.2 \%$ were males with the majority living in town(55.8\%) compared to the $44.2 \%$ that lived in villages. $81.1 \%$ of the respondents were Christians with the rest being Muslims and the majority of these respondents (55.8\%)were students at secondary level followed by $22.1 \%$ at primary level with the least being $18.9 \%$ and $3.2 \%$ of university and uneducated levels respectively.

\subsection{Table 1: Table showing demographics}

\section{Knowledge of adolescents on NCDs risk fac-} tors.

To ascertain the depth of knowledge about NCDs, respondents were asked several specific and nonspecific questions on whether they had heard about NCDs, source of information, identifying from the given list, whether it is easier to prevent NCDs Than communicable diseases, risk factors for NCDs and about specific cardiovascular risk factors. From the study findings, 86(90.5\%) reported having heard about NCDs and only $9(9.5 \%)$ had not with the majority having gotten the information from teachers and parents 56(58.9\%) followed by health workers and friends with the same percentage of $13.7 \%$ with the least information having been gotten from media 6(6.3\%).

The majority of the respondents were able to identify at least two of the NCDs from the list given i.e. 57(60\%) with hypertension and cancer being the most identified diseases.

Concerning knowledge about the risk factors for NCDs, the majority of the respondents 73 (76.8\%) were able to identify at least two of the risk factors with smoking and physical activity being the most identified risk factors. Specific questions about NCDs risk factors were answered also in that $52(54.7 \%)$ were able to identify that NCDs are preventable compared to the $43(45.3 \%)$ that couldn't.79(83.2\%) were able to know that eating foods with sugar predisposes one to NCDs while the majority that is $91 \%$ said that smoking affects one's health. The findings also considered knowledge about cardiovascular disease being the leading cause of mortality among the NCDs and a lesser percentage i.e. 41 (43.2\%) had ever heard of cardiovascular diseases compared to the 54(56.9\%) that had never heard about them.

\subsection{Table: 2 showing general knowledge about NCDs}

\subsection{Table3: Frequency Table showing knowledge of NCDs}

The findings show significant association between the levels of knowledge of the respondents who lived in towns compared to those who lived in towns with a p.value of 0.028 , education levels with a $p$ value equaling to 0.0181 .The social demographic variables of age, gender, religion and occupation were not significantly associated with knowledge about NCDs risk factors as seen in the table 4 below.

\subsection{Table 5: Frequency table for knowledge of risk factors for NCDs}

With the social demographic characteristic association and the NCDs risk factors, only area of residence and levels of education showed a great association on the knowledge about NCDs risk factors with the $p$ values of 0.076 and 0.00143 respectively as shown in table 5 below.

\subsection{Table 5: Table showing the association between \\ demographics and knowledge of risk factors for NCDs \\ 5.6 Table 6: Table showing association between demographics and prevention on NCDs}

Social demographic variables associated with knowledge about NCDs prevention were the age of the participant with a $p$ value of 0.009 and levels of 
Table 1. showing demographics

\begin{tabular}{lll}
\hline Variables & Fre- & Percentage (\%) \\
& quency(n) & \\
Age 10-15 15-19 & 2867 & 29.570 .5 \\
Sex male female & 4253 & 44.255 .8 \\
Tribe Munyankore Mutoro Mukiga Others(Mufubira Muganda, Rwandese) & 696713 & 72.66 .37 .413 .7 \\
Residence Town Village & 5342 & 55.844 .2 \\
Religion Pentecostal Protestant Muslim Catholic Others (SDA) & 6331836 & 6.334 .718 .9 \\
& 2 & 37.92 .1 \\
Level of education not educated primary secondary university and college & 3215318 & 3.222 .155 .8 \\
& & 18.9 \\
Occupation Employee house maid business student others(,mechanic, & 116825 & 1.11 .16 .386 .3 \\
tailoring dressing hair) & & 5.3 \\
\hline
\end{tabular}

Table 2. showing general knowledge about NCDs

\begin{tabular}{|c|c|c|}
\hline Variables & $\begin{array}{l}\text { Fre- } \\
\text { quency }\end{array}$ & Percentage (\%) \\
\hline Have you ever heard about non communicable diseases (NCDS?) Yes No & 869 & 90.59 .5 \\
\hline $\begin{array}{l}\text { Source of information health worker friend teacher and parents me- } \\
\text { dia(tv,radio,newspaper)none }\end{array}$ & $\begin{array}{l}131356 \\
67\end{array}$ & $\begin{array}{l}13.713 .758 .9 \\
6.37 .4\end{array}$ \\
\hline $\begin{array}{l}\text { Non communicable diseases are easier to prevent than communicable diseases } \\
\text { Yes No }\end{array}$ & 5243 & 54.745 .3 \\
\hline What do you think are the main reasons for developing cancer? Diabetes Hered- & 38676 & 3.28 .46 .380 .0 \\
\hline ity Alcohol misuse Smoking Obesity & 2 & 2.1 \\
\hline Does smoking affect one's health? Yes No Don't know & 9113 & 95.81 .13 .2 \\
\hline Can eating foods with a lot of sugar affect blood sugar? Yes No Don't know & 79412 & 83.24 .212 .6 \\
\hline . Does high blood sugar cause health problems Yes No Don't know & 82112 & 86.31 .112 .6 \\
\hline $\begin{array}{l}\text { Does physical activity help to prevent non communicable diseases? Yes No Don't } \\
\text { know }\end{array}$ & 69188 & 72.618 .98 .4 \\
\hline Do you think occurrence of NCDs can be prevented Yes No Don't know & 701114 & 73.711 .614 .7 \\
\hline $\begin{array}{l}\text { How can they be prevented physical activity quit smoking proper eating habits } \\
\text { others(doctor's advice, checkup) }\end{array}$ & $\begin{array}{l}44816 \\
27\end{array}$ & $\begin{array}{l}46.38 .416 .8 \\
28.4\end{array}$ \\
\hline
\end{tabular}

Table 3. Frequency Table showing knowledge of NCDs

\begin{tabular}{lll}
\hline Variable & Fre- & Per- \\
quency & cent \\
NCDs(hypertension, diabetes, stroke,asthma,epilepsy,cancer, heart attack) knowing at & 57 & 60.0 \\
least two & 32 & 33.7 \\
knowing at least one & 6 & 6.3 \\
not knowing any & 6 & \\
\hline
\end{tabular}




\section{Table 4. Table showing association between knowledge of NCDs and demographics}

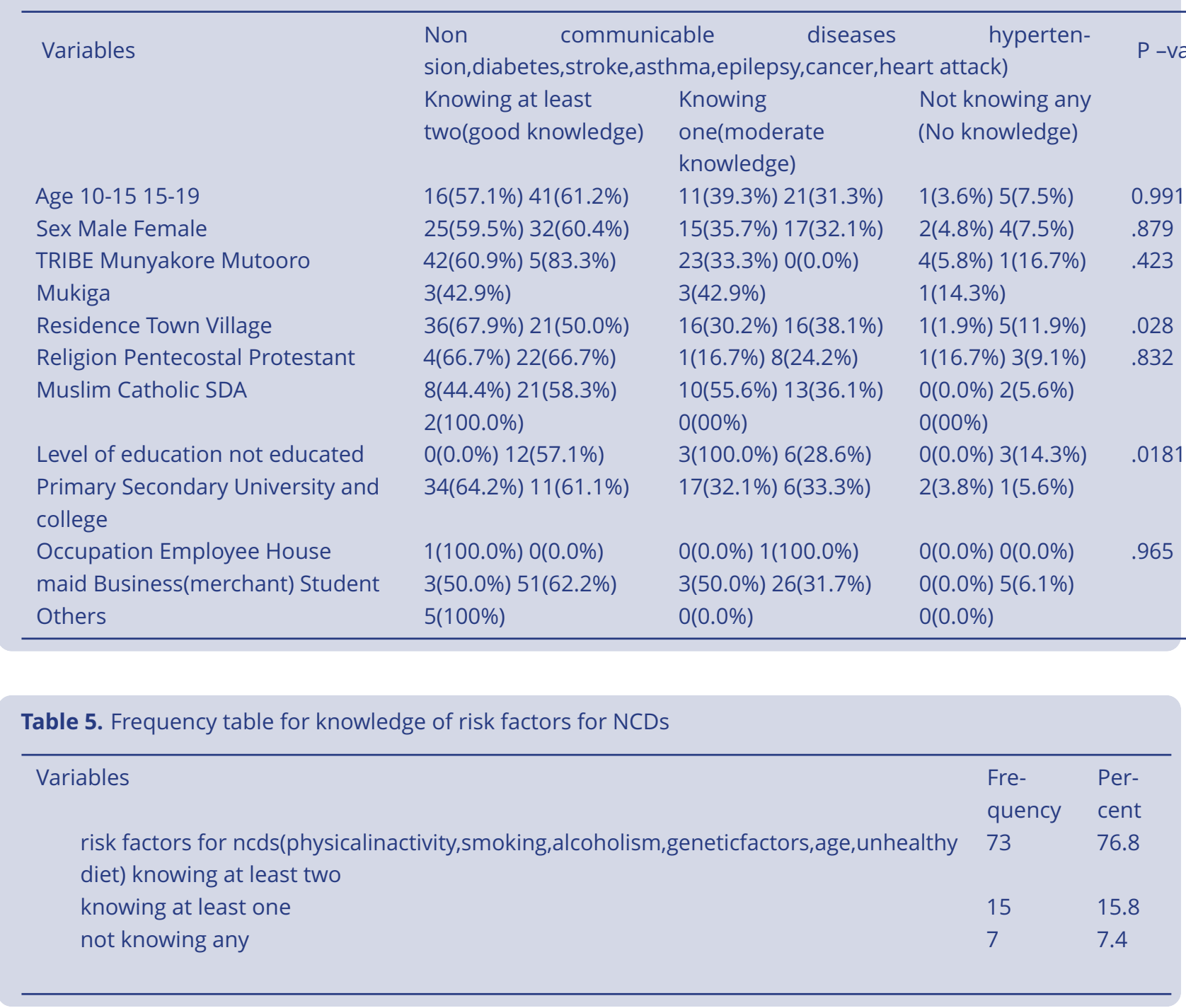

Table 6. showing the association between demographics and knowledge of risk factors for NCDs

\begin{tabular}{|c|c|c|c|c|}
\hline \multirow[t]{2}{*}{ Variables } & \multicolumn{4}{|c|}{$\begin{array}{l}\text { Risk factors for NCDs(physicalinactivity,smoking,alcoholism, geneticfactors, age, unhealthy } \\
\text { diet) }\end{array}$} \\
\hline & knowing at least two & $\begin{array}{l}\text { knowing at least } \\
\text { one }\end{array}$ & not knowing any & \\
\hline Age 11-15 16-19 & $22(78.6 \%) 51(76.1 \%)$ & $2(7.1 \%) 13(19.4 \%)$ & $4(14.3 \%) 3(4.5 \%)$ & 0.588 \\
\hline Sex Male Female & $31(73.8 \%) 42(79.2 \%)$ & $8(19.0 \%) 7(13.2 \%)$ & $3(7.1 \%) 4(7.5 \%)$ & .686 \\
\hline TRIBE munyankore mutoro & $52(75.4 \%) 5(83.3 \%)$ & $12(17.4 \%) 1(16.7 \%)$ & $5(7.2 \%) 0(0.0 \%)$ & .840 \\
\hline mukiga & $5(71.4 \%)$ & $1(14.3 \%)$ & $1(14.3 \%)$ & \\
\hline Residence Town Village & $45(84.9 \%) 28(66.7 \%)$ & $5(9.4 \%) 10(23.8 \%)$ & $3(5.7 \%) 4(9.5 \%)$ & .076 \\
\hline Religion Pentecostal Protestant & $4(66.7 \%) 26(78.8 \%)$ & $0(0.0 \%) 4(12.1 \%)$ & $2(33.3 \%) 3(9.1 \%)$ & .373 \\
\hline \multirow[t]{2}{*}{ Muslim Catholic SDA } & $14(77.8 \%) 27(75.0 \%)$ & $3(16.7 \%) 8(22.2 \%)$ & $1(5.6 \%) 1(2.8 \%)$ & \\
\hline & $2(100 \%)$ & $0(00 \%)$ & $0(00 \%)$ & \\
\hline Level of education Not educated & $1(33.3 \%) 16(76.2 \%)$ & $1(33.3 \%) 2(9.5 \%)$ & $1(33.3 \%) 3(14.3 \%)$ & .00143 \\
\hline $\begin{array}{l}\text { Primary Secondary University and } \\
\text { college }\end{array}$ & $42(79.2 \%) 14(77.8 \%)$ & $9(17.0 \%) 3(16.7 \%)$ & $2(3.8 \%) 1(5.6 \%)$ & \\
\hline Occupation Employee House maid & $1(100.0 \%) 1(100.0 \%)$ & $0(0.0 \%) 0(0.0 \%)$ & $0(0.0 \%) 0(0.0 \%)$ & .666 \\
\hline Business(merchant) Student & $4(66.7 \%) 65(79.3 \%)$ & $2(33.3 \%) 11(13.4 \%)$ & $0(0.0 \%) 6(7.3 \%)$ & \\
\hline Others & $5(100 \%)$ & $0(0.0 \%)$ & $0(0.0 \%)$ & \\
\hline
\end{tabular}


Table 7. showing association between demographics and prevention on NCDs

\begin{tabular}{|c|c|c|c|c|}
\hline \multirow{2}{*}{ Variables } & \multicolumn{3}{|c|}{ Do you think occurrence of NCDs can be prevented } & \multirow{2}{*}{$p$-value } \\
\hline & Yes & No & Don't know & \\
\hline Age 11-15 16-19 & $14(50.0 \%) 56(83.6 \%)$ & $8(28.6 \%) 3(4.5 \%)$ & $6(21.4 \%) 8(11.9 \%)$ & .009 \\
\hline Sex Male Female & $31(73.8 \%) 39(73.6 \%)$ & $3(7.1 \%) 8(15.1 \%)$ & $8(19.0 \%) 6(11.3 \%)$ & .622 \\
\hline \multirow[t]{2}{*}{ TRIBE munyankore mutoro mukiga } & $55(79.7 \%) 4(66.7 \%)$ & $4(5.8 \%) 1(16.7 \%)$ & $10(14.5 \%)$ & .985 \\
\hline & $6(85.7 \%)$ & $0(0.0 \%)$ & $1(16.7 \%) 1(14.3 \%)$ & \\
\hline Residence Town Village & $40(75.5 \%) 30(71.4 \%)$ & $10(18.9 \%) 1(2.4 \%)$ & $3(5.7 \%) 11(26.2 \%)$ & .0106 \\
\hline Religion Pentecostal protestant & $4(66.7 \%) 28(84.8 \%)$ & $0(0.0 \%) 2(6.1 \%)$ & $2(33.3 \%) 3(9.1 \%)$ & .803 \\
\hline Muslim Catholic SDA & $8(44.4 \%) 28(77.8 \%)$ & $7(38.9 \%) 2(5.6 \%)$ & $3(16.7 \%) 6(16.7 \%)$ & \\
\hline Level of education Not educated & $1(33.3 \%) 10(47.6 \%)$ & $1(33.3 \%) 5(23.8 \%)$ & $1(33.3 \%) 6(28.6 \%)$ & .003 \\
\hline $\begin{array}{l}\text { Primary Secondary University and } \\
\text { college }\end{array}$ & $44(83.0 \%) 15(83.3 \%)$ & $3(5.7 \%) 2(11.1 \%)$ & $6(11.3 \%) 1(5.6 \%)$ & \\
\hline Occupation Employee House maid & $1(100.0 \%) 0(0.0 \%)$ & $0(0.0 \%) 0(0.0 \%)$ & $0(0.0 \%) 1(100.0 \%)$ & .926 \\
\hline Business(merchant) Student & $6(100.0 \%) 60(73.2 \%)$ & $0(0.0 \%) 11(13.4 \%)$ & $0(0.0 \%) 11(13.4 \%)$ & \\
\hline
\end{tabular}

education with $p=0.003$ and there was no any other social demographic characteristics that showed any significance as shown in the table below.

\subsection{Table 7: Table showing practices of risk factors for NCDs \\ Practices of adolescents towards NCDs risk fac- tors}

Concerning diet that has fruits, the majority $60(62.4 \%)$ took fruits at least once, twice or thrice in a week while 35(37.6\%) took fruits more frequently as in four, five times or days as they are indicated in the table above. About vegetable intake,57(60\%) percent took a diet with vegetables once, twice, or thrice in a week compared to the $38(40 \%)$ that took a diet with vegetables many times a week.44(35.8\%) took sugary foods more often i.e. many times in a week compared to the $61(64.3 \%)$ that took them less often. Concerning the intake of solid fats or fried food, 52(54.7\%) took fried foods more occasionally in a week and a day compared to the $43(45.3 \%)$ that took fried diet less often.

\section{Discussion}

\section{Knowledge of adolescents about NCDs risk fac- tors}

Physical activity, avoiding alcohol consumption, quitting smoking and healthy dietary practices are the main ways through which NCDs occurrences can be prevented. Recent studies on NCDs have shown that knowledge of NCDs among adolescents is almost universal. The knowledge that adoles- cents have about NCDs risk factors is expected to determine their prevention practices/behaviour.

The study findings showed that more than half of the respondents had knowledge about NCDs risk factors as the majority were able to identify more than two risk factors from the many listed factors and the main risk factors identified were unhealthy diet and alcohol consumption. The above findings are in a line with the study carried out by Murang et al., (2017) in Brazil whereby more than half of the adolescents had adequate knowledge about specifically the two major risk factors that were being asked about in that study and that was physical inactivity and poor eating habits however the high level of knowledge about the NCDs risk factors demonstrated in the study may be due to different NCDs information sources and the educational level as most of the participants were secondary or university students, and they could have possibly gotten the knowledge information from the different course subjects they could have studied during study possibly in biology classes. The most source of information was through parents and teachers, significantly among the other sources mentioned by the respondents was from health worker and friends and these findings are contrary from those of Bakogiani et al., (2012) where the adolescents had gotten the information from mainly healthy workers and their parents. Half of the participants were able to know that NCDs are easier to prevent compared to the $45.3 \%$ that said no to the question. Regarding knowledge questions of specific risk factors, almost all of the respondents were able to 
Table 8. showing practices of risk factors for NCDs

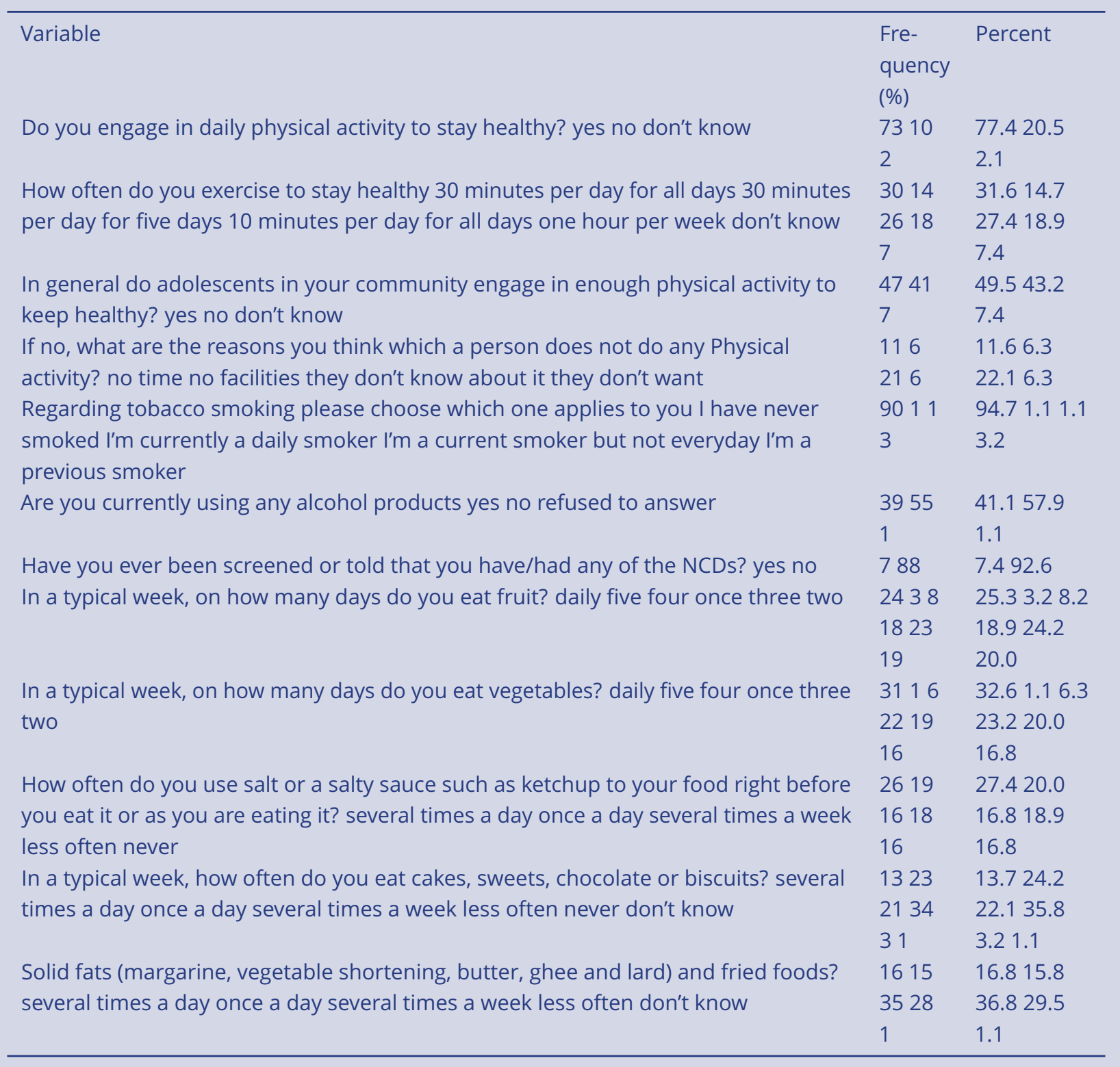

know that smoking affects ones healthy however of this percentage, lesser respondents only knew how it affects healthy by responding that it caused cancer. The vast knowledge levels were seen in both the educated and the non-educated, those who lived in towns and those who lived in villages, and the old and young adolescents and this is possibly due to the massive awareness campaigns that have been running over different media platforms like radios, TVs, newspapers and different health camps set up to sensitize the population about the health prevention measures of NCDs and the results are in correspondence with the ones of the research carried out by Barbara et al., (2013) whereby the majority of the respondents knew the health hazards of smoking by age eleven while the major- ity also knew that eating foods with a lot of sugar and high blood sugar respectively caused healthy related problems and this was because there were increased cancer and hypertension cases in the region. However, these knowledge percentages are contrary to the research findings by Murang et al., (2017) whereby the majority of children knew that physical activity was good for their health and half the respondent stated that they had 'enough' physical activity, though almost half of them did not know about the recommended time for doing these physical activities.

\section{Practices of Adolescents towards NCDs risk} factors

According to data from different European countries, the average age of exposure to these NCDs 
risk factors has decreased over the last three decades with increasing adolescents reporting physical inactivity, poor eating habits, smoking, and alcoholism before the age of 16 years. This is in line with the current findings where the mean age of all the above risk factors is 15 years and the declining age of first exposure has been proffered as one possible explanation for the increase in the number of NCDs cases all over the world (Mazur et al., 2013).

In this study, $77.4 \%$ reported being engaging in daily physical activity to stay healthy while only a few reported being doing enough physical activity to stay healthy while a portion of respondents didn't know whether they were doing enough or little physical activity and this could be possible because of the environmental nature as most of the adolescents like playing with each other at school and while they are at their home places and also walking while going to town, church or gardening. This is almost in line with the study conducted by Murang et al., (2017) in Brazil whereby the majority of children did physical activity good to stay healthy, only half stated that they had 'enough' physical activity, and almost half of them did not know about the recommended time for doing these physical activities. This is because most of the population is not well versed with the WHO recommended time for physical activity possibly because no one has put in the effort to equip the adolescents with such kind of information. In this study, there was a direct correlation of physical activity with the area of residence whereby adolescents who stayed in villages had good physical activity practicing habits compared to the ones that stayed in towns possibly because adolescents in adolescents are usually involved in household chores of earning a living with their parents like gardening, collecting firewood among others and there is also the availability of big free available land where they can get involved in sports which is not the case for town adolescents, yet they stay longer on television watching. Those who did not do the recommended physical activity gave out the different reasons for not doing so and the majority was that they didn't know about it yet others claimed that they did not have time. These findings were similar to a study conducted on 1060 Chinese children, aged 12-15 years, where the children were found to suffer from insufficient physical activity; with girls being less active than boys (Wang et al., 2016). Similarly, a study from Malta conducted on 1126 boys and girls, aged 10-11 years, found that only $39 \%$ and $10 \%$ of its boys and girls met the physical activity guidelines (Mukherjee et al., 2016). A cross-sectional study conducted on 3051 adolescents from 10 European cities also found insufficient physical activity amongst their youth (Cocker et al., 2011).

Concerning the risk factor of alcoholism, many adolescents were currently using alcohol products and the risk of alcohol drinking was higher between 14 and 18 years of age and was greatly lower with religious affiliation mostly the Moslems. The high percentage would possibly be due to peer influence that is usually encountered by adolescents and the high index of curiosity. The higher levels of alcohol consumption seen with this study fining are also evident in other research articles for example a study done by Aryal et al in Nepal in 2015 showed that $54.5 \%$ of the adolescents had contact with alcohol products with curiosity and not living with their parents were the main reasons for alcohol consumption. Despite the high prevalence, this figure is lower than that found in the Brazilian National School of Health survey which reports a consumption value of $71.4 \%$ among adolescent school children (Malta et al., 2011).

Considering the risk factor of inappropriate healthy eating habits, considerations were mainly on the weekly fruit and vegetable servings, foods with solid fat or fried foods, and foods with high salt and sugary content and the findings are discussed below; Concerning diet that has fruits, the majority took fruits at least once, twice or thrice in a week while the little percentage took fruits more frequently as in four, five times or days as they are indicated in the results. This is because the fruits and vegetables are not readily available and the little available ones are at a higher price hence seeing the majority of the adolescents not taking in a recommended serving of fruits and vegetables. The above findings are contrary to the study done in Boston by Murang et al., (2017) which found out that the majority of children studied had good eating habits, where, the majority of them had at least one serving of fruits and vegetables and did not have more than one serving of fast food per day. A lesser percentage of adolescents took sugary foods more often i.e. many times in a week compared to the majority that took them less often. Concerning the intake of solid fats or fried food, more than half of the participants took fried foods more occasion- 
ally in a week and a day compared to the lesser percentage that took fried diet less often.

\section{Limitations:}

The findings may not be generalizable to the entire adolescents in the community since not all of them seek health care services from the government facility.

Additionally, the study was facility-based so it may not be representative of the entire community as the health care seeking rate is not $100 \%$ in the area.

\section{Conclusion}

This study shows that adolescents have a good level of knowledge on NCDs and their risk factors; however, they present insufficient knowledge on specific NCDs and specific risk factors hence an implication that the adolescents still need more information on NCDs risk factors. The study also reflects poor practices and behaviours of the adolescents towards this risk factor prevention. This confirms the saying knowledge doesn't predict behavioural outcome and that the best predictor of behavioural change is time rather than knowledge.

\section{Recommendations:}

Integration of primary health care services that mainly emphasizes the prevention measures as the ministry of health should recruit and deploy health teams that will mainly be targeting adolescents as they equip them with knowledge about the NCDs risk factors. Health education talks should be integrated into all the health centres in Uganda to increase awareness of NCDs risk factors as teachers were the main source of information compared to the health workers.

Lastly, more research is recommended especially to determine the predictors of NCDs risky factor behaviours among adolescents, also more research is needed about knowledge and practices of adolescents about specific NCDs risk factors. A community-based study may also be pursued to determine the levels of knowledge and practices of adolescents in the community as this study might have underestimated the levels since it was health center-based and a qualitative-based approach should be used to dig deep into the adolescent practices towards NCDs risk factors.

\section{Acknowledgment}

First and foremost, the entire honour goes to God the Almighty for the guidance, strength, power of the mind, protection, and for giving me a healthy life to undertake this research study

I also take this opportunity to thank my family especially my parents for being there for me, for the emotional support, the knowledge, financial support, and experiences shared with me during the study, and to my lovely brothers and sister.

I would like to thank my research supervisor, Mr. Muhumuza Allan for the direction he provided through his timely advice and constructive feedback.

Finally am grateful to lecturers, friends, and colleagues especially the BNS class of 2016 who generously contributed their time and effort to help me while undertaking this course your support and contributions were a blessing.

List of Acronyms and Abbreviations.

NCDs Non-communicable diseases

WHO World health organization

LMICS Low and middle-income countries

HBM Health belief Model

HP Health Promotion

BMI Body mass index

UNCDA Uganda Non-Communicable Diseases Alliance.

KHCIV Kabwohe Health Centre IV.

OPD Outpatient department.

CVD Cardio Vascular Diseases

DM Diabetes Mellitus

KP Knowledge and practices

\section{Operational terms and definitions}

Non-communicable diseases: These are diseases that result in long-term health management, are caused by multiple risk factors, and have a noncontagious origin. They may also be termed chronic diseases (WHO 2015)

Risk factors: Is any attribute, characteristic, or exposure of an individual that increases the likelihood of developing a disease or injury (WHO 2015)

Lifestyle practices: A set of habitual behaviours which affect either positively or negatively, the health of an individual. This study will focus on lifestyle practices about tobacco use, alcohol consumption, diet, and physical activity.

Health services: These are services dealing with diagnosis, treatment, and management of diseases to restore or maintain the health of patients. 
Attitude: How an adolescent thinks and behaves with regards to NCDs

Adolescent: The Nations, for statistical purposes defines an adolescent as those persons between the ages of 10 and 19 years, without prejudice to other definitions by member states. 


\section{Table 9. References}

1) Barbara J. G., Dianne I. R., (2013). The smoking attitudes, knowledge, intent, and Behaviors of adolescents and young adults: Implications for nursing practice Journal of Nursing Education and Practice, January Vol. 3, No. 1.https://doi.org/10.5430/jnep.v3n1p40

2) De Cocker K., Ottevaere C., Sjostrom M., Moreno LA., Wärnberg J., \& Valtueña J., (2011) Self-reported physical activity in European adolescents: results from the HELENA (Healthy Lifestyle in Europe by Nutrition in Adolescence) study. Public Heal Nutr; 14(2):246-54.https://doi.org/10.1017/S1368980010000558PMid:202 36565

3) Gamage A. U., \& Jayawardana P. L., (2017). "Knowledge of non-communicable diseases and practices related to healthy lifestyles among adolescents, in state schools of a selected educational division in Sri Lanka." BMC Public Health18(1): 64https://doi.org/10.1186/s12889-017-4622-zPMid:28747202 PMCid:PMC5530461

4) Giannoula D., Bakogianni., Spiridoula C., Goutsou, Maria V Liti., Sophia I., Rizopoulou, Konstantinos M., Nikolakopoulos \& Nikoleta M.N., (2012). Knowledge, attitude, and practice of cervical cancer screening among Greek students: a short report Int J Adolesc Med Health https://doi.org/10.1515/ijamh.2012.047PMi $\mathrm{d}: 23183733$

5) Kaddumukasa, M., Kayima, J., Kaddumukasa, M.N. (2015). Knowledge, attitudes and perceptions of stroke: a cross-sectional survey in rural and urban Uganda. BMC Res Notes 8, 819 https://doi.org/10.1186/s 13104-015-1820-6PMid:26708348 PMCid:PMC4691295

6) Malta DC., Silva JB Junior., (2013). Brazilian Strategic Action Plan to Combat Chronic Non-communicable Diseases and the global targets set to confront these diseases by 2025: a review. Epidemiol Serv Saúde. 22(1).

7) Mazur A., Matusik P., Revert K., Nyankovskyy S., Socha P., Binkowska-Bury M., (2013). Childhood obesity: knowledge, attitudes, and practices of European pediatric care providers. Pediatrics;132(1):e100-8.https://d oi.org/10.1542/peds.2012-3239PMid:23753085

8) Mondo CK., Otim MA., Akol G., MuSoke R., Orem J., (2013). The prevalence and distribution of non-communicable diseases and their risk factors in Kasese district, Uganda: cardiovascular topics. Cardiovascular J Afr; 24:52-7https://doi.org/10.5830/CVJA-2012-081PMid:23736126 PMCid:PMC3721879

9) Murang Z.Z., Tuah N.A.A., \& Naing,L. (2017).Knowledge, attitude and practice towards eating and physical activity among primary school children in Brunei: a cross-sectional study. International Journal of Adolescent Medicine and Healthhttps://doi.org/10.1515/ijamh-2017-0118PMid:29190212

10) Nunes, H. E., E. C. Goncalves, J. A. Vieira \& D. A. Silva (2016). "Clustering of Risk Factors for Non-Communicable Diseases among Adolescents from Southern Brazil." PLoS One11(7): e0159037https://d oi.org/10.1371/journal.pone.0159037PMid:27434023 PMCid:PMC4951139

11) Rahamathulla MP., Sha MM., (2020). Frequency and Awareness of Risk Factors of Non-Communicable Diseases among University Students in Saudi Arabia. Pak J Med Sci.36(4):740-745.https://doi.org/10.12669/ pjms.36.4.2400PMid:32494266 PMCid:PMC7260916

12) Wesonga, R.D., Guwatudde, S. K. Bahendeka, G. Mutungi, F. Nabugoomu \& J. Muwonge (2016). "Burden of cumulative risk factors associated with non-communicable diseases among adults in Uganda: evidence from a national baseline survey."Int J Equity Health15(1): 195https://doi.org/10.1186/s12939-016-0486-6PMi d:27905949 PMCid:PMC5133748

13) WHO (2018) STEPS: A framework for surveillance. World Health Organization, Available: https://www.wh o.int/ncd_surveillance/en/steps_framework

14) WHO.(2010). Global status report on non-communicable diseases. https://www.who.int/nmh/publicatio 